\title{
BMJ Open Financing of surgery and anaesthesia in sub-Saharan Africa: a scoping review
}

\author{
Martilord Ifeanyichi (D) , ${ }^{1,2}$ Ellis Aune, ${ }^{1}$ Mark Shrime (D) , ${ }^{3,4}$ Jakub Gajewski (D) , ${ }^{3}$ \\ Chiara Pittalis (D) , John Kachimba (D) , ${ }^{5}$ Eric Borgstein, ${ }^{7}$ Ruairi Brugha (D) , \\ Rob Baltussen, ${ }^{1}$ Leon Bijlmakers (i) ${ }^{1}$
}

To cite: Ifeanyichi M, Aune E, Shrime M, et al. Financing of surgery and anaesthesia in sub-Saharan Africa: a scoping review. BMJ Open 2021;11:e051617. doi:10.1136/ bmjopen-2021-051617

- Prepublication history and additional supplemental material for this paper are available online. To view these files, please visit the journal online (http://dx.doi.org/10.1136/ bmjopen-2021-051617).

Received 25 March 2021 Accepted 22 September 2021

Check for updates

(C) Author(s) (or their employer(s)) 2021. Re-use permitted under CC BY-NC. No commercial re-use. See rights and permissions. Published by BMJ.

For numbered affiliations see end of article.

Correspondence to Dr Martilord Ifeanyichi; Mifeanyichi@gmail.com

\section{ABSTRACT}

Objective This study aimed to provide an overview of current knowledge and situational analysis of financing of surgery and anaesthesia across sub-Saharan Africa (SSA). Setting Surgical and anaesthesia services across all levels of care-primary, secondary and tertiary. Design We performed a scoping review of scientific databases (PubMed, EMBASE, Global Health and African Index Medicus), grey literature and websites of development organisations. Screening and data extraction were conducted by two independent reviewers and abstracted data were summarised using thematic narrative synthesis per the financing domains: mobilisation, pooling and purchasing.

Results The search resulted in 5533 unique articles among which 149 met the inclusion criteria: 132 were related to mobilisation, 17 to pooling and 5 to purchasing. Neglect of surgery in national health priorities is widespread in SSA, and no report was found on national level surgical expenditures or budgetary allocations. Financial protection mechanisms are weak or nonexistent; poor patients often forego care or face financial catastrophes in seeking care, even in the context of universal public financing (free care) initiatives. Conclusion Financing of surgical and anaesthesia care in SSA is as poor as it is underinvestigated, calling for increased national prioritisation and tracking of surgical funding. Improving availability, accessibility and affordability of surgical and anaesthesia care require comprehensive and inclusive policy formulations.

\section{INTRODUCTION}

Over $70 \%$ of the world population lack access to safe, timely and affordable surgical and anaesthesia care, with an estimated nine out of ten people affected in sub-Saharan Africa (SSA). ${ }^{1}$ The Lancet Commission on Global Surgery (LCGS) has set a timeline of 2030 for $80 \%$ of the global population to have access to such care, ${ }^{2}$ and as a strategy, it also recommended that low-income and middle-income countries (LMICs) develop National Surgical, Obstetric, and Anaesthesia Plans (NSOAPs), structured into five domains: service delivery, infrastructure, workforce, information management and financing. ${ }^{2}$ The financing system is critical to the achievement of

\section{STRENGTHS AND LIMITATIONS OF THIS STUDY}

$\Rightarrow$ This study was conducted based on standard guidelines, including Arksey and 0'Malley (2005), Levac et al (2010), the Joanna Briggs Institute (2020), and PRISMA Statement and its extension for scoping reviews.

$\Rightarrow$ It benefited from a comprehensive published and grey literature search strategy designed with the support of institutional bibliographers.

$\Rightarrow$ The use of two independent reviewers and an arbiter ensured meticulosity while minimising biases in the review process.

$\Rightarrow$ It thoroughly examines the situation and the current knowledge on the financing of surgery and anaesthesia in sub-Saharan Africa.

$\Rightarrow$ Findings from one country may not represent the situation or be applicable in other countries in the region.

universal access to surgical care, as it directly affects availability, accessibility and affordability of services.

Health financing is the "function of a health system concerned with the mobilisation, accumulation and allocation of money to cover the health needs of the people, individually and collectively, in the health system'. ${ }^{3}$ Three cardinal but interrelated functions of health financing are distinguished: revenue collection, resource pooling and purchasing. ${ }^{3}$ Resource mobilisation refers to the ways in which revenues are raised and collected, including government budgetary allocations (from taxes for instance), health insurance premiums, out-of-pocket (OOP) payments and donor funding. The pooling function refers to the mechanisms of accumulation of prepaid funds on behalf of populations in order to address financial challenges at the point of service delivery. Pooling delinks expected health expenditures from patients' ability to pay $^{4}$ and ideally protects people from catastrophic or impoverishing expenditure while accessing health services. The most common pooling mechanisms are 
government tax revenues pooling for health and health insurance schemes. The purchasing function refers to the payment systems for health goods and services provided.

To improve surgical financing, the LCGS recommended that national governments undertake the following: cover basic surgical care within Universal Health Coverage (UHC); pool risks in a single pool and reduce payments at point of service; track financial flows for surgery through national health accounts; and use value-based purchasing with risk-pooled funds. Further, as progress assessment indicators, they proposed that surgical expenditure be reported as a percentage of GDP and as a percentage of annual healthcare expenditure and that OOP payments on surgery, and catastrophic and impoverishing expenditure on surgery be monitored. It is noteworthy that catastrophic and impoverishing expenditures on surgery have been included in the World Bank World Development Indicators (WDI). ${ }^{5}$

Since the LCGS report in 2015, five SSA countries have launched and are implementing their NSOAPs: Rwanda, Zambia, Tanzania, Nigeria and Madagascar. ${ }^{6}$ Two other countries - Senegal and Ethiopia - had adopted strategic surgical plans prior to the LCGS report. Dozens of other SSA countries are either in the process of or have committed to the development of NSOAPs. Development of health policies requires baseline analyses. ${ }^{7}$ In the development of the Tanzania NSOAP, a situational analysis conducted by Nyberger $e t a l^{8}$ using a systematic review of literature guided a stakeholder discussion to directly inform the NSOAP priorities. In the financing domain, however, the review found only limited evidence-highlighting a paucity of research on the financing of surgery, especially at country levels. A collation of evidence from different countries may be beneficial to national health policy makers, and as more countries develop and adopt NSOAPs, there is a need for more evidence to guide these investments towards improving surgical care in SSA.

This study aimed therefore to provide a general overview of the evidence on financing of surgery in SSA, describe the situation, and identify research gaps to guide future research efforts.

\section{METHODS}

\section{Framework}

Given the aim of the study, a scoping review was adopted. 'A scoping review or scoping study is a form of knowledge synthesis that addresses an exploratory research question aimed at mapping key concepts, types of evidence, and gaps in research related to a defined area or field by systematically searching, selecting and synthesising existing knowledge '. ${ }^{9}$ Beyond mapping evidence, scoping reviews are particularly useful for summarising and disseminating research findings to policy makers, practitioners and consumers who might otherwise be unable to engage in such tasks themselves due to time and resource constraints. ${ }^{10}$
This study followed the five-step approach described by Arksey and O'Malley ${ }^{10}$ who provided the first methodological framework for conducting scoping reviews: (1) identifying the research question; (2) identifying relevant studies; (3) study selection; (4) charting the data; (5) collating, summarising and reporting results. This was supplemented with the recommendations of Levac et $a l^{11}$ and the Joanna Briggs Institute (JBI) ${ }^{12}$

\section{Research question}

Broadly, this study was underpinned by the question: What is known from the existing literature about financing of surgery and anaesthesia in SSA?

Specific subquestions that guided the study are as follows:

Regarding financing of surgery and anaesthesia in SSA:

1 . What is the situation?

2. What mechanisms (if any) mobilise, pool and allocate resources for services?

3. What strategies have been trialled to improve access?

4. What has been the progress since the 2015 publication of the LCGS?

5. What specific challenges are identified?

6. What policy options are recommended for improvement?

\section{Search strategy and data sources}

The search query was designed based on three search blocks-'surgery and anaesthesia', 'health financing' and 'sub-Saharan Africa'-with the assistance of institution bibliographers. The primary query was built on PubMed, in an iterative fashion, using a list of already identified relevant articles. The final PubMed query was adapted and applied to all the other databases. The full search string is included in online supplemental material S1.

We searched four bibliographic databases without any language restrictions: Global Health on 22 July 2020, and PubMed, Embase and African Index Medicus on 24 July. Searches were restricted to articles published between January 2010 and July 2020, to capture a fairly current situation, while covering approximately 5 years before and after the LCGS report. Conference proceedings, dissertations and animal studies were excluded. Additionally, we performed snowballing by hand-searching the references in the identified articles for further possibly relevant articles. A grey literature search was conducted on Google, and websites of WHO, World Bank, and USAID were also manually searched.

\section{Screening process and management}

All search results were first imported into EndNote X9 for deduplication and then exported to Rayyan, ${ }^{13}$ a web and mobile app designed for systematic reviews, for title and abstract screening. The initial screening was performed independently by authors MI and EA. In case of discrepancy, MI and EA reviewed the abstract together, and if no agreement could be reached, author LB was consulted to make the final decision. In the second round, full 
texts of included articles were reviewed independently and discussed by authors MI and EA, and LB was again consulted in case of irresolvable discrepancies. French articles were handled solely by author LB who possesses a full professional proficiency in French Language.

The Population, Concept, and Context (PCC) framework described by the $\mathrm{JBI}^{12}$ was used to define the inclusion/exclusion criteria, which are included in table 1. Relevance criteria were applied in a hierarchical fashion: each article was assessed first on whether or not it pertained to SSA, then whether or not it pertained to surgery, and lastly whether it covered financing of surgery. All available sources were included.

\section{Data charting and analysis}

Data charting (ie, extraction) was performed using a customised form in Excel 2020 based on the JBI guidelines. ${ }^{12}$ All empirical evidence related to any of the functions of health financing was extracted, maintaining an approach broad enough to include even evidence related to the absence of these functions and their implications for surgery delivery and access. In addition, non-empirical but unique or sufficiently compelling (as adjudged by the two independent researchers) insights on challenges or policy options for surgical financing were also extracted. In doing these, a bottom-up thematic analysis was employed ${ }^{14}$ : emerging themes were identified and coded within the functional domains. This was subsequently followed by axial coding, that is, linking conceptually related themes together. Descriptive statistics were computed for the article characteristics.

\section{Summarisation and reporting of results}

A narrative synthesis was employed in summarising the results of the research question, maintaining the three financing domains as the overarching themes. Results are presented as per PRISMA Statement ${ }^{15}$ and its extension for scoping reviews (see online supplemental material S2). ${ }^{16}$

\section{Patient and public involvement}

Patients or the public were not involved in the design, conduct, or reporting, or dissemination plans of our research.

\section{RESULTS}

Following deduplication, our search resulted in 5533 unique articles. Text and abstract screening produced 229 articles, of which 149 met the inclusion criteria following full text reading (figure 1). Most (132) were in English and nine were in French. Two-thirds of the articles were published between 2015 and 2020. In terms of geographical spread, the studies covered 28 countries: Nigeria had the highest number of articles (34), followed by Uganda (15) and Kenya (14). Eight articles were non-specific, while several articles cut across more than one country. Details are presented in online supplemental material S3.

The majority of articles focused on specific (or combinations of) surgical conditions or subspecialties ( $\mathrm{N}=121$; $81 \%$ ), while 28 were non-specific or dealt with surgical systems generally. Obstetrics (mostly caesarean sections) had the highest number of articles (39), followed by ophthalmology (24; mostly cataract procedures) and oncology (17). The breakdown of the articles per specialty is presented in figure 2.

The majority of the articles were empirical $(\mathrm{N}=138$; 92\%); 10 were opinion/editorial papers, while 1 was a technical brief. The empirical articles included 112 quantitative studies (81\%), 12 qualitative studies, 11 mixed-methods studies and 3 systematic reviews. Most

Table 1 Inclusion and exclusion criteria

\begin{tabular}{|c|c|c|}
\hline & Inclusion criteria & Exclusion criteria \\
\hline
\end{tabular}




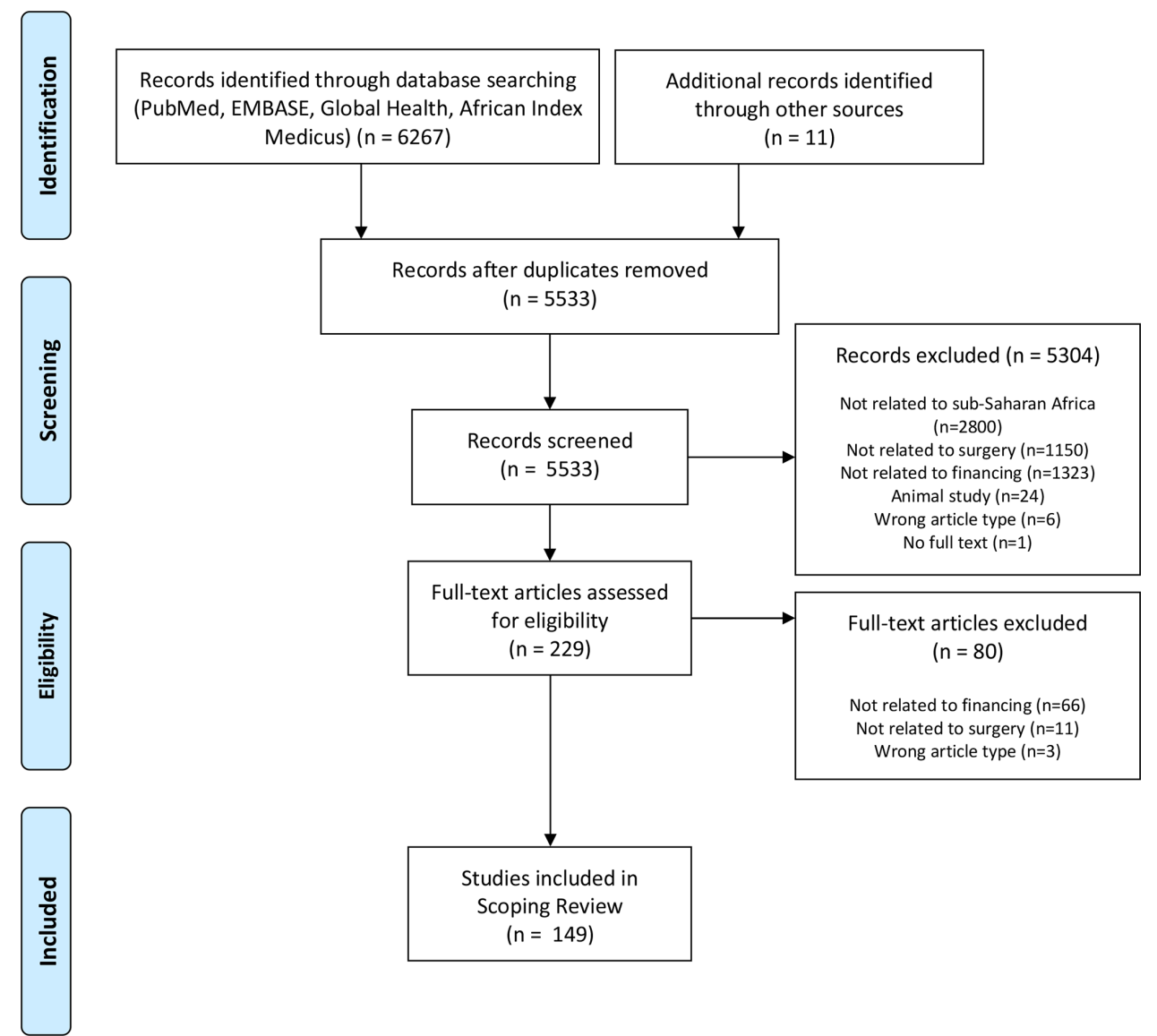

Figure 1 PRISMA flowchart of the search process.

of the quantitative articles were descriptive $(\mathrm{N}=81$; $72 \%) ; 12$ were analytical (cohort or case-control); 5 were modelling studies and 14 were quasi-experimental

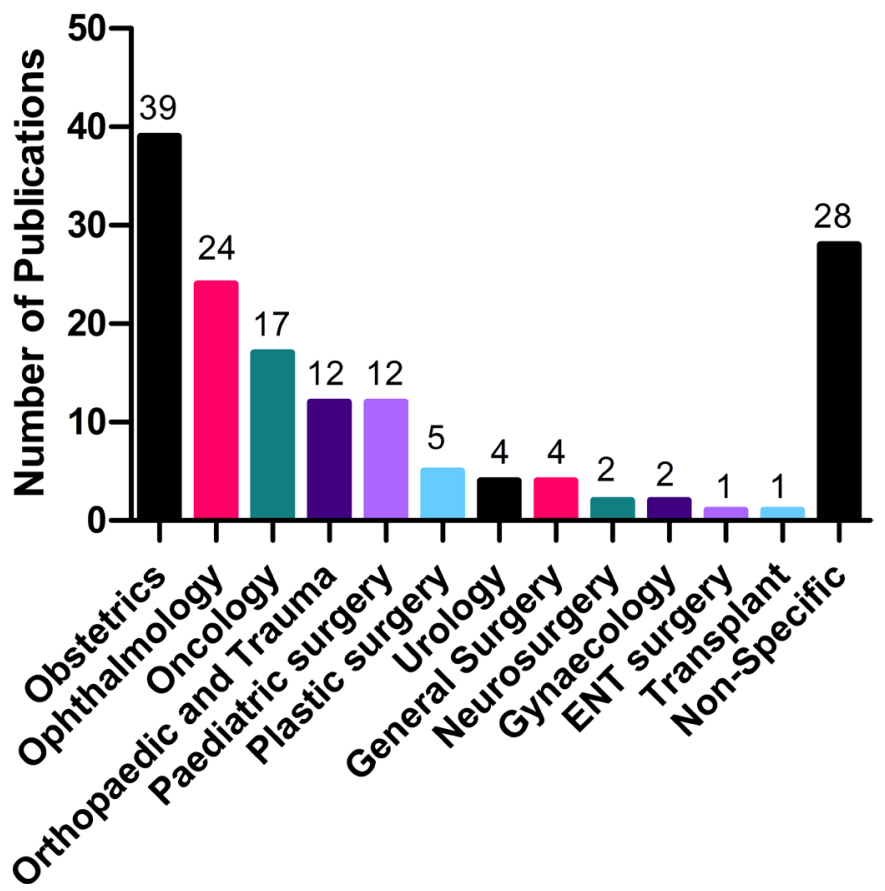

Figure 2 Breakdown of the selected articles by surgical specialties. (including four interrupted time series analyses, two propensity score matching analyses, two difference-indifference analyses and six uncontrolled before-andafter studies).

The bulk of the articles related to the pooling and risk protection function of health financing $(\mathrm{N}=132 ; 89 \%)$; 17 related to financial resource mobilisation $(11 \%)$ and 5 to purchasing $(3 \%)$. Some of the articles related to more than one domain. In the next sections, we present a thematic narrative of the data extracted from the various articles.

Resource mobilisation and budgetary allocations to surgery Seventeen articles explored the resource mobilisation for or allocations to surgery. No report of national or subnational level budgetary allocations or actual expenditures on surgery was found. There was evidence of poor prioritisation of surgery in government plans and UHC programmes in SSA generally: in a systematic review of National Health Strategic Plans (NHSPs) of 48 SSA countries by Citron et $\mathrm{l}^{17}, 19 \%$ of NHSPs had no mention of surgery or surgical conditions and $63 \%$ had five or fewer mentions of surgery. Compared with HIV and malaria that had 3772 mentions across all the plans, surgery had only 376 mentions. While $33 \%$ of policies had no surgical targets, all had measurable targets for HIV and TB control. 
Seven articles had data on revenue sources for surgery at the hospital level, with OOP payments, ${ }^{18-21}$ government support ${ }^{22}$ and donor funds ${ }^{21}{ }^{22}$ identified as the biggest sources of the operational funds. In Ekenze and others' systematic review of studies published between January 2007 and November 2016 that reported the specific funding of paediatric surgeries in SSA, OOP was the predominant source of funding $(91.4 \%)$, followed by non-governmental organisation (NGO) funding $(60 \%){ }^{21}$

Regarding hospital expenditure on surgery, four studies were relevant. ${ }^{182-24}$ In a retrospective cross-sectional study of the human and financial constraints to essential surgery at eight district hospitals (DHs) in Tanzania, Uganda, Mozambique, the DHs spent $7 \%-14 \%$ of their operational funds on surgery, representing an annual per capita expenditure of US $\$ 0.05-0.14 .{ }^{23}$ The bulk of this expenditure $(3 \%-8 \%$ of total operational cost) was attributed to obstetrics alone. Comparable proportions $(16 \%-17 \%)$ were also reported at two DHs in Malawi. ${ }^{22}$

Several approaches to increasing the funding of surgery were recommended in the articles. In the review by Ekenze $e t a l^{21}$, the main suggestions were increased funding by national governments and by international organisations $(85.7 \%)$, the establishment or improvement of health insurance schemes $(60 \%)$ and the sustained use of charities and medical missions $(42.9 \%)$. Several papers in our review emphasised public-private partnerships, ${ }^{25} 26$ as well as scale-up of health insurance coverage ${ }^{27-29}$ Rather than attempting to reinvent the wheel in the face of structural and economic constraints, Frimpong-Boateng and Edwin ${ }^{30}$ called on national governments to tweak and leverage on the existing market models to scale-up local production of surgical consumables, for example, by replacing non-profitable tyre production with gloves and boots production, or production of cotton wool and gauze alongside or in place of cloth.

Reddy $e t a l^{31}$ advocated moving beyond the traditional funding sources. They suggested innovative financing instruments that have been applied in other global health initiatives, such as voluntary solidarity levy (as in Unitaid), voluntary contributions (PRODUCT(RED)), performance-based instruments (GAVI), and securities and bonds (International Finance Facility for Immunisation (IFFI) and The Children's Investment Fund Foundation (CIFF)).

\section{Pooling/Risk protection}

A total of 132 articles provided evidence related to pooling functions and financial protection. Eight subthemes emerged. Some themes portrayed dysfunctionality of the financial protection systems and their implications for patients: financial barriers to access of care, transport cost barriers, OOP and catastrophic/impoverishing expenditure, payment coping mechanisms and low willingness to pay. Others explored commonly available financial protection interventions: universal public financing and health insurance. Other studies evaluated how best to simultaneously achieve health benefits, financial protection, equity and efficiency in surgical care delivery. Several articles cut across multiple themes. The eight thematic clusters and selected illustrative studies are presented below:

\section{Financial barriers to accessing surgical care}

The 55 articles in this cluster investigated patient-reported obstacles or challenges to surgical care and reported 'costs' or 'lack of finances' as a major reason for not seeking $^{32}$ and for not obtaining surgical care (following recommendation $)^{33} 34$ and as a reason for experiencing delays in accessing ${ }^{26}{ }^{35}$ or dropping out of the surgical continuum of care. ${ }^{36}$ In a population-based survey to assess the surgical burden of diseases in Uganda, $66 \%$ of the people living with treatable surgical conditions cited cost as the reason for not seeking care. ${ }^{32}$ A systematic review of barriers to cataract surgeries in Africa cautioned against face value interpretation of such findings, as 'costs' are sometimes convenient masks for factors other than inability to pay, such as unwillingness to pay and complex family decision-making dynamics. ${ }^{38}$

\section{Transport cost barrier}

Closely related to the above financial access barriers, 12 articles highlighted the particular challenges presented by transport costs to accessing surgical care, even in situations where medical treatments are provided free of charge. In interviews and focus group discussions with 64 patients living with lymphatic filariasis in Ahanta West District of Ghana, $64 \%$ cited indirect costs (transport and loss of wages) as the most prohibitive factor to seeking care, despite the cost of surgery being covered under the National Health Insurance Scheme (NHIS). ${ }^{39}$

\section{P and catastrophic and impoverishing expenditures}

Twenty-six publications explored OOP and catastrophic or impoverishing expenditure incidences and reported high rates. In a study that modelled global country-level comparison of the financial burden of surgery, the risk of financial hardship from surgery was highest in SSA, with up to $90 \%$ of patients facing the risk of catastrophe and up to $100 \%$ at risk of impoverishment. ${ }^{40}$ Despite that health services are provided free of charge at public facilities in Malawi, 90\%-97\% of patients with hernia still suffer catastrophic expenditures. ${ }^{41}$

\section{Patient coping mechanisms and economic consequences of $00 \mathrm{P}$} payments

Twelve articles provided insights into how households of surgical patients mobilise resources for OOPs as well as the adjustments they make in their daily lives to cope with the impact. Despite the free obstetric care policy in Malawi, $31 \%$ of the women who receive such care borrow money, $24 \%$ sell assets, $17 \%$ use their savings, while others get help from family members abroad $(17 \%)$ or their local social network (12\%). ${ }^{42}$ Reported compromises in every day spending in the face of catastrophic surgical expenditure include decreases in food consumption ${ }^{42} 43$ and withdrawal of wards/children from school,,${ }^{42} 44$ even 
as some households remain in debts several years after the surgery. $^{42} 43$

\section{Willingness to pay (WTP)}

Three articles investigated the willingness of surgical patients to pay for services. Even though most of the patients surveyed were willing to pay 'something', their WTP was usually lower than the actual cost of getting the surgery. ${ }^{45} 46$ For instance, in a hospital-based survey of patients who had received free surgery in Malawi, participants expressed willingness to pay a median of US\$3, which was substantially lower than US\$60, the estimated combined cost of screening, transport, feeding, accommodation, medicines and surgery. ${ }^{46}$ Studies showed that WTP for surgical services increases remarkably with counselling on the benefit ${ }^{47}$ and actual cost of the surgery, ${ }^{38}$ and increased trust in providers. ${ }^{38}$

\section{Universal public financing (UPF) or free services}

In a bid to protect patients from financial hazards, governments in SSA have often abolished user fees in public hospitals, either for all or certain categories of care. Twenty-three articles evaluated the implementation or the effects of such measures on service utilisation and/ or financial protection.

Free maternal and under-five care in Sierra Leone was associated with a five-fold increase in the volume of paediatric surgeries in the 20 months after its introduction compared with 20 months before at a public tertiary hospital; above-five surgeries increased by only $17 \%{ }^{48}$ Perhaps partly reflecting differences in methodologies, conflicting reports were obtained on the effects of fee removal on caesarean section rates, with various studies reporting nil impact, ${ }^{49}{ }^{50}$ increases $^{51}$ and (possibly supplier-induced) excessive caesarean section (CS) rates. $^{52}$

Several papers reported significant financial hazards despite the free care policies, due to informal direct medical costs, indirect medical costs (particularly transportation) or both. Patients often encountered informal direct medical OOPs due to frequent drug stockouts, equipment breakdowns, unofficial fees ${ }^{445153-55}$ or outright bribery of health workers to 'facilitate' access to so-called free care. ${ }^{51525657}$

The failure of UPF programmes across SSA to provide adequate financial protection has had adverse implications for equitable access to care, as evidenced in six studies. Pro-rich inequities were documented in use of CS several years after introduction of free obstetric care policies in Ghana, ${ }^{589}$ Mali $^{6061}$ and Benin. ${ }^{61}$

Valuable insights were gained into the challenges confronting successful implementation of UPF policies. Poor funding and delayed or incomplete hospital reimbursements were commonly reported, ${ }^{54}$ as were poor supervision and accountability mechanisms, ${ }^{62}{ }^{63}$ lack of clarity on policy provisions, for example, which items or services should be paid for by patients, ${ }^{56} 63$ poor specification and targeting of beneficiaries, ${ }^{52}$ demotivation of hospital workers due to declines in hospital finances, ${ }^{54}$ and resistance among health professionals manifesting as 'rent-seeking' and corrupt practices to augment sagging personal incomes. ${ }^{525662}$

\section{Health insurance}

Twenty-three articles provided insights into health insurance coverage and the degree of protection it provides for surgery patients in SSA. Health insurance coverage rates among cross-sections of emergency surgery patients studied were generally poor: about $3 \%$ in Nigeria, ${ }^{64} 6 \%$ in Mali, $^{65} 8 \%$ in Tanzania, ${ }^{66} 17 \%$ in Madagascar ${ }^{67}$ and $23 \%$ in Kenya. ${ }^{68}$ Coverage rates stood out in Ghana $(67 \%)$, courtesy of National Health Insurance Fund (NHIF), ${ }^{69}$ and Rwanda (98\%) with its Community Health Insurance Fund (CHIF) ${ }^{70}$ Instructively, higher rates were reported among elective surgery patients- $45 \%$ in Nigeria ${ }^{71}$ and Tanzania, $^{72}$ and $90 \%$ in Kenya ${ }^{73}$-indicating a disproportionately higher uptake of elective services by the insured who are mostly the better off, at the expense of the poor. $^{71} 72$ This review found evidence of some level of financial protection from health insurance. For instance, in a study among surgical patients admitted over a period of 8 months at a teaching hospital in Ghana, 58\%-87\% of insured patients faced catastrophic expenditure compared with $83 \%-98 \%$ among the uninsured. The insured spent an average of $39 \%$ of their annual income on care compared with $61 \%$ for the uninsured. ${ }^{74}$ Like the UPF programmes however, concerns of inequities remain. $^{75}$

Various studies reported specific challenges associated with national health insurance schemes in SSA. In Nigeria for instance, NHIS is considered bureaucratic and elitist, covering only civil servants and people of higher social status. ${ }^{27} 71$ Beneficiaries have also reported lack of clarity about what services are covered or not, as well as confusion about payment and reimbursement mechanisms. ${ }^{27}$ From the provider perspective, there have been worries about NHIS reimbursement rates being lower than the actual service costs, forcing some private providers to exit the programme, as well as delays in reimbursements which affect running of the facility. ${ }^{71}$ Another major and common challenge recorded was shallowness of benefit coverages. Even though the insured had lower chances of catastrophic expenditure, a large proportion of them still suffered catastrophes ${ }^{74}$ and still employed 'extreme' payment coping strategies. ${ }^{43}$ Although poor awareness of NHIF was noted as an issue in SSA, studies indicate patient education and sensitisation again make a huge difference. ${ }^{77}$

\section{Balancing financial protection, equity and efficiency}

An extended cost-effectiveness analysis by Shrime et $a l^{78}$ evaluated the health, financial and equity impacts of nine common NGO and government strategies towards improving access to surgery in Uganda. It showed that only mobile surgical programmes and policies that simultaneously address surgical service scale-up (providers), 
OOP expenditure for surgery and (the often ignored) transport cost can provide health and financial benefits, equitably and efficiently, simultaneously. A similar study in Ethiopia arrived at the same conclusion. ${ }^{79}$

\section{Purchasing/Provider payment}

Five articles had findings related to the purchasing function. Surgery providers in public institutions in SSA are generally salaried workers, ${ }^{80} 81$ but poor remuneration is widespread. In a multicentre survey of 41 paediatric surgeons across 11 Francophone countries in SSA, the average salary in 2008 was just about 450 Euros per month (ranging from 120 to 1400 Euros). ${ }^{81}$

Two studies explored the effect of payment mechanisms on hospital operations. A before-and-after study in Burkina Faso showed that both government and household expenditure on CS increased after the free delivery policy changed from retrospective fee-for-service payment to prospective fee-for-service payment. ${ }^{82}$ The other study showed that the introduction of performancebased financing at DHs in Rwanda was associated with an increase in the number of CS from 60 to 140 per quarter over a 5 -year period. ${ }^{83}$

\section{DISCUSSION}

Today, domestic resource mobilisation for surgery in SSA is grossly deficient due to the double jeopardy of an overall constrained fiscal space for health and poor political prioritisation of surgery. Using Shiffman and Smith's analysis framework for assessing global health priorities, Frimpong-Boateng and Edwin ${ }^{30}$ attributed the neglect to 'the failure to communicate a clear policy need using powerful ideas that take advantage of the political contexts of the times'. There is clearly a need for champions, including practitioners, scholars, public servants and professional societies who would leverage political affiliations and use empirical evidence to project surgery into political consciousness at different levels, as has been witnessed in the few countries that have adopted NSOAPs. ${ }^{684} 85$

Another direct consequence of the national level neglect of surgery in SSA is the literature lacuna on surgical allocations and expenditures, as revealed in this review, contrary to the LCGS recommendations. In a further search for possible insights, we reviewed five SSA NSOAPs that were accessible via Google (Ethiopia, Nigeria, Rwanda, Tanzania and Zambia) and found that none had any data related to national financial allocations to surgery or actual expenditures, while only the Nigeria and Rwanda NSOAPs had information on hospital allocations to surgery. This finding is neither new nor limited to SSA: Meara et $a l^{2}$ reviewed 958 national health accounts published between 1996 and 2010 in LMICs and reported that only Georgia and Kyrgyzstan routinely reported expenditures on surgery ${ }^{2}$; and a 2015 systematic review of UHC programmes in LMICs showed surgeries were systematically excluded from national
UHC packages. ${ }^{86}$ This limited evidence shows the lack of substantial progress, 5 years after the LCGS recommendations, suggesting minimal scholarly interest in the subject. The upward trend recorded in the volume of studies from 2015 is nonetheless welcome and should be sustained and intensified.

Poor pooling functions across SSA mean that access to surgical care still correlates strongly with socioeconomic status, resulting, among the poor, in disinclination to seek care, catastrophic expenditures for those who dare to seek care, disruptions in care stream and consequential inequities in health outcomes affecting especially the poor. The successes recorded with CHIF in Rwanda ${ }^{87}$ and NHIF in Ghana ${ }^{88}$ might serve as examples to be built on by other countries. Meanwhile, as laudable as health insurance and UPF interventions are, the most important message from this study is that just removing or subsidising user fees is not enough. Aside from the associated technical complexities that must be addressed, numerous other non-medical cost elements hampering universal access to surgical care remain, including transport, food, accommodation and loss of earnings. As such, even if all the direct medical costs were covered at the national or facility level, some patients would remain simply too poor to obtain even 'free' surgical care. ${ }^{89}$ The particular contexts of low-income countries ought to be understood and addressed appropriately using more comprehensive policy designs.

This study reveals important priorities for future research. First, there is a need to explore the current national level mobilisation and allocation patterns and track the available resources throughout the system to inform best policy directions. ${ }^{7}$ Second, numerous studies have established the vulnerabilities faced by the poor due to inadequacies in protection measures, but few have explored optimal financial protection strategies given the socioeconomic realities in SSA. ${ }^{78}$ More evidence in this regard will aid contextualised policy formulation. Further, the literature is particularly scanty on the purchasing aspects of surgical services: a deeper understanding of interactions between hospital reimbursement patterns and personnel remuneration systems on one hand and surgical service delivery on the other hand will engender value-based purchasing mechanisms and ensure maximisation of surgical output with the limited available resources. ${ }^{2}$ Lastly, as national and subnational governments in SSA continue to pursue free obstetric care policies, the literature remains divided on their exact impacts on CS rates. More rigorous studies are recommended to resolve the conflicts and explore the factors that may account for different outcomes in different countries.

Wide variations found in approaches to the estimation of catastrophic expenditures across the articles call for a special note. Health expenses are described as 'catastrophic' if they exceed a certain threshold proportion of household income/expenditure or capacity to pay, ${ }^{91}$ but lack of unanimity remains in the thresholds applied. ${ }^{4291}$ In addition, cost elements considered in the calculations 
also differed, with some covering only direct medical cost, ${ }^{40}$ others including direct non-medical costs ${ }^{29} 67$ and still others extending to indirect costs. ${ }^{415392}$ Moreover, definitions of direct and indirect costs were inconsistent. Given the cardinal position this metric has assumed in financial protection analyses, uniformity in approaches is particularly imperative, and to achieve this, we advocate adherence to the definition and methodology adopted by the WHO and the World Bank for indicator 3.8.2 of the sustainable development goals, which monitors the financial protection dimension of universal health coverage. $^{93} 94$

\section{Limitations}

The first limitation of this study is that associated with scoping reviews generally, which is that they often do not evaluate the quality of the evidence presented, thus putting the results at a high risk of bias and diminishing the possibilities of drawing definitive conclusions therefrom. Further, while our study aimed to collate findings from different countries for the consumption of policymakers and stakeholders in individual countries, it is not clear to what extent findings or policy lessons from one country could be applicable in another country. Overall, however, we think that the use of two parallel reviewers and an arbiter, in line with best practices, improved the quality of the work and that the work nonetheless provides some useful insights for policymakers across SSA.

\section{CONCLUSION}

This study has provided a situational analysis of financing of surgery and anaesthesia in SSA while summarising the current knowledge on the subject. The resources available for surgery are limited due in part to the neglect of surgery in national priorities, making it difficult for hospitals to provide the full package of surgical services. Surgery services are unaffordable for the great majority of populations, resulting in financial catastrophes and/ or impoverishments. Findings in this review could guide national policy makers in SSA, especially those implementing or developing NSOAPs, in adopting more comprehensive and inclusive measures to enhance access to SOA services, while steering research towards critical unanswered questions.

\footnotetext{
Author affiliations

${ }^{1}$ Department for Health Evidence, Radboud University Medical Centre, Nijmegen, The Netherlands

${ }^{2}$ EMAI Health Systems and Health Services Consulting, Nijmegen, The Netherlands ${ }^{3}$ Institute of Global Surgery, Royal College of Surgeons in Ireland, Dublin, Ireland ${ }^{4}$ Department of Global Health and Social Medicine, Harvard Medical School, Boston, Massachusetts, USA

${ }^{5}$ Department of Public Health and Epidemiology, Royal College of Surgeons in Ireland, Dublin, Ireland

${ }^{6}$ Department of Surgery, University of Zambia University Teaching Hospital, Lusaka, Zambia

${ }^{7}$ College of Medicine, University of Malawi, Blantyre, Malawi
}

Twitter Martilord Ifeanyichi @Martilord
Acknowledgements We are grateful to Dr Henk Broekhuizen (Department of Social Sciences, Wageningen University) for his help in the conceptualisation of the study. We also wish to appreciate information specialists Elmie Peters and Dr On Ying Chan of Radboud University Medical Library, and Paul Murphy of Royal College of Surgeons in Ireland (RCSI) Library, for their technical assistance in the development and execution of the literature search strategy; and Jos Peters of Radboud University Medical Library who assisted in the acquisition of the full texts of the articles.

Contributors Ml conceived the study. Ml, EA and LB designed the study, conducted the search and analysed the data. Ml and EA drafted the first manuscript. MI, EA, $M S, J G, C P, J K, E B, R B r u g h a$, RBaltussen and LB contributed to data interpretation, and critically reviewed and edited the first draft. MI, EA, MS, JG, CP, JK, EB, RBrugha, RBaltussen and LB read and approved the final manuscript. LB supervised the study.

Funding This work was supported by European Commission's Horizon 2020 Framework Programme, under grant agreement no: 733391, as part of the Scaling up Safe Surgery for District and Rural Populations in Africa (SURG-Africa) project.

Competing interests None declared.

Patient consent for publication Not applicable.

Provenance and peer review Not commissioned; externally peer reviewed.

Data availability statement Data are available upon reasonable request. Extra data is available by emailing author Ml (Martilord.ffeanyichi@radboudumc.nl).

Supplemental material This content has been supplied by the author(s). It has not been vetted by BMJ Publishing Group Limited (BMJ) and may not have been peer-reviewed. Any opinions or recommendations discussed are solely those of the author(s) and are not endorsed by BMJ. BMJ disclaims all liability and responsibility arising from any reliance placed on the content. Where the content includes any translated material, BMJ does not warrant the accuracy and reliability of the translations (including but not limited to local regulations, clinical guidelines, terminology, drug names and drug dosages), and is not responsible for any error and/or omissions arising from translation and adaptation or otherwise.

Open access This is an open access article distributed in accordance with the Creative Commons Attribution Non Commercial (CC BY-NC 4.0) license, which permits others to distribute, remix, adapt, build upon this work non-commercially, and license their derivative works on different terms, provided the original work is properly cited, appropriate credit is given, any changes made indicated, and the use is non-commercial. See: http://creativecommons.org/licenses/by-nc/4.0/.

\section{ORCID iDs}

Martilord Ifeanyichi http://orcid.org/0000-0003-0611-6795

Mark Shrime http://orcid.org/0000-0002-3546-9867

Jakub Gajewski http://orcid.org/0000-0003-0440-6051

Chiara Pittalis http://orcid.org/0000-0003-3465-9850

John Kachimba http://orcid.org/0000-0002-3735-5134

Ruairi Brugha http://orcid.org/0000-0003-0729-0197

Leon Bijlmakers http://orcid.org/0000-0003-2252-0579

\section{REFERENCES}

1 Alkire BC, Raykar NP, Shrime MG, et al. Global access to surgical care: a modelling study. Lancet Glob Health 2015;3:e316-23.

2 Meara JG, Leather AJM, Hagander L, et al. Global surgery 2030: evidence and solutions for achieving health, welfare, and economic development. Lancet 2015;386:569-624.

3 WHO. Health systems: improving performance, 2000. Available: https://www.who.int/whr/2000/en/[Accessed 05 Jun 2020].

4 Evans DB, Etienne C. Health systems financing and the path to universal coverage. Bull World Health Organ 2010;88:402.

5 The World Bank. World development indicators, 2019. Available: https://databank.worldbank.org/source/world-developmentindicators [Accessed Mar 2021].

6 Truché P, Shoman H, Reddy CL, et al. Globalization of national surgical, obstetric and anesthesia plans: the critical link between health policy and action in global surgery. Global Health 2020;16:1.

7 WHO. Situation analysis of the health sector, 2016. Available: https:// www.who.int/healthsystems/publications/nhpsp-handbook-ch3/en/ [Accessed 15 Jun 2020].

8 Nyberger K, Jumbam DT, Dahm J, et al. The situation of safe surgery and anaesthesia in Tanzania: a systematic review. World J Surg 2019;43:24-35. 
9 Colquhoun $\mathrm{HL}$, Levac D, O'Brien KK, et al. Scoping reviews: time for clarity in definition, methods, and reporting. J Clin Epidemiol 2014;67:1291-4.

10 Arksey H, O'Malley L. Scoping studies: towards a methodological framework. Int J Soc Res Methodol 2005;8:19-32.

11 Levac D, Colquhoun H, O'Brien KK. Scoping studies: advancing the methodology. Implement Sci 2010;5:69.

12 Micah Peters CG, Mclnerney P, Munn Z. Scoping Reviews. In: Aromataris EMZ, ed. JBI manual for evidence synthesis. JBI, 2020. https://synthesismanualjbiglobal

13 Mourad Ouzzani HH. Zbys Fedorowicz, and Ahmed Elmagarmid Rayyan - a web and mobile APP for systematic reviews, 2016. Available: https://rayyan.qcri.org/welcome [Accessed 30 Jul 2020]

14 Braun V, Clarke V. Using thematic analysis in psychology. Qual Res Psychol 2006;3:77-101.

15 Moher D, Liberati A, Tetzlaff J, et al. Preferred reporting items for systematic reviews and meta-analyses: the PRISMA statement. PLoS Med 2009;6:e1000097.

16 Tricco AC, Lillie E, Zarin W, et al. PRISMA extension for scoping reviews (PRISMA-ScR): checklist and explanation. Ann Intern Med 2018;169:467-73.

17 Citron I, Chokotho L, Lavy C. Prioritisation of surgery in the National health strategic plans of Africa: a systematic review. World J Surg 2016;40:779-83.

18 Iverson KR, Garringer K, Ahearn O, et al. Mixed-Methods assessment of surgical capacity in two regions in Ethiopia. Br J Surg 2019;106:e81-90.

19 DeGregorio G, Manga S, Kiyang E, et al. Implementing a feefor-service cervical cancer screening and treatment program in Cameroon: challenges and opportunities. Oncologist 2017;22:850-9.

20 Rakotondrajoa P, Rakotomamonjy T, Baptiste RJ, et al. Achieving self-sustainability of service delivery in an eye care program in Madagascar using time-driven activity based costing. BMC Health Serv Res 2020;20:205.

21 Ekenze SO, Jac-Okereke CA, Nwankwo EP. Funding paediatric surgery procedures in sub-Saharan Africa. Malawi Med J 2019;31:233-40.

22 Cornelissen D, Mwapasa G, Gajewski J, et al. The cost of providing District-Level surgery in Malawi. World J Surg 2018;42:46-53.

23 Kruk ME, Wladis A, Mbembati N, et al. Human resource and funding constraints for essential surgery in district hospitals in Africa: a retrospective cross-sectional survey. PLoS Med 2010;7:1-11.

24 Sion M, Rajan D, Kalambay $\mathrm{H}$, et al. A resource planning analysis of district hospital surgical services in the Democratic Republic of the Congo. Glob Health Sci Pract 2015;3:56-70.

25 Adoga A, Nimkur T, Silas O. Chronic suppurative otitis media: socioeconomic implications in a tertiary hospital in northern Nigeria. Pan Afr Med J 2010;4.

26 Nnabugwu I, Ugwumba F, Ede J. Second-Phase delay in accessing major elective surgeries from a public tertiary health institution in Nigeria: the role of financial constraints. International Journal of Medicine and Health Development 2019;24:96-94.

27 Obembe T, Fonn S. Affording unavoidable emergency surgical care - The lived experiences and payment coping strategies of households in Ibadan metropolis, Southwestern Nigeria. PLoS One 2020;15:e0232882.

28 Ugalahi MO, Olusanya BA, Fagbemi OO, et al. Delays in uptake of surgery for childhood cataract at a child eye health tertiary facility in sub-Saharan Africa. Eur J Ophthalmol 2020;30:280-3.

29 Urua U, Osungbade K, Obembe T, et al. A cost analysis of road traffic injuries in a tertiary hospital in south-west Nigeria. Int $J$ Inj Contr Saf Promot 2017;24:510-8.

30 Frimpong-Boateng K, Edwin F. Surgical leadership in Africa challenges and opportunities. Innov Surg Sci 2019;4:59-64.

31 Reddy CL, Peters AW, Jumbam DT, et al. Innovative financing to fund surgical systems and expand surgical care in low-income and middle-income countries. BMJ Glob Health 2020;5:e02375.

32 Butler EK, Tran TM, Fuller AT, et al. Pilot study of a population-based survey to assess the prevalence of surgical conditions in Uganda. Surgery 2015;158:764-72.

33 Bouglouga O, Lawson-Ananissoh LM, Bagny A, et al. [Stomach cancer: Epidemiological, clinical and histological aspects at the Lome Campus teaching hospital (Togo)]. Med Sante Trop 2015;25:65-8.

34 Lerman BJ, Alsan M, Chia NJ, et al. Beyond infrastructure: understanding why patients decline surgery in the developing world: an observational study in Cameroon. Ann Surg 2017;266:975-80.

35 Onyebuchi AK, Lawani LO, Nkwo PO, et al. Determinants of decision-to-intervention time in the management and therapeutic outcome of emergency gynecological surgeries in South East Nigeria. Ther Clin Risk Manag 2014;10:577-82.
36 Lankoande M, Bonkoungou P, Traore SIS, et al. Cancellation of elective surgical procedures in the University teaching hospital center Yalgado Ouedraogo in Burkina Faso: incidence, reasons and proposals for improvement. Southern African Journal of Anaesthesia and Analgesia 2016;22:140-4.

37 Takongmo S, Yomi J, Guifo ML. Neoadjuvant chemotherapy in the treatment of advanced and inflammatory breast cancer in Yaounde (Cameroon). Journal Africain du Cancer / African Journal of Cancer 2011:3:175-9.

38 Aboobaker S, Courtright P. Barriers to cataract surgery in Africa: a systematic review. Middle East Afr J Ophthalmol 2016;23:145-9.

39 Stanton MC, Best A, Cliffe M, et al. Situational analysis of lymphatic filariasis morbidity in Ahanta West district of Ghana. Trop Med Int Health 2016;21:236-44.

40 Shrime MG, Dare A, Alkire BC, et al. A global country-level comparison of the financial burden of surgery. $\mathrm{Br} J$ Surg 2016;103:1453-61.

41 Bijlmakers L, Wientjes M, Mwapasa G, et al. Out-of-pocket payments and catastrophic household expenditure to access essential surgery in Malawi - A cross-sectional patient survey. Ann Med Surg 2019;43:85-90.

42 Arsenault C, Fournier P, Philibert A, et al. Emergency obstetric care in Mali: catastrophic spending and its impoverishing effects on households. Bull World Health Organ 2013;91:207-16.

43 Nnabugwu II, Nwankwor C, Ugwumba F. Gaining access to major elective surgeries in a public tertiary health institution in Southeast Nigeria: evaluating household payment coping strategies. Annals of African Surgery 2019;16:69-74.

44 Anderson GA, Ilcisin L, Kayima P, et al. Out-Of-Pocket payment for surgery in Uganda: the rate of impoverishing and catastrophic expenditure at a government Hospital. PLoS One 2017; 12:e0187293

45 Ibrahim N, Ramke J, Pozo-Martin F, et al. Willingness to pay for cataract surgery is much lower than actual costs in Zamfara state, Northern Nigeria. Ophthalmic Epidemiol 2018;25:227-33.

46 Dean WH, Sherwin JC, Kumwenda S, et al. Willingness to pay for cataract surgery in post-operative cataract patients in rural Malawi. Ophthalmic Epidemiol 2012;19:265-71.

47 Dim CC, Onyedum CC, Dim NR, et al. Cervical cancer screening among HIV-positive women in Nigeria: an assessment of use and willingness to pay in the absence of donor support. $J$ Int Assoc Provid AIDS Care 2015;14:241-4.

48 Groen RS, Kamara TB, Nwomeh BC, et al. Free health care for under 5 year olds increases access to surgical care in Sierra Leone: an analysis of case load and patient characteristics. World J Surg 2013;37:1216-9.

49 McKinnon B, Harper S, Kaufman JS, et al. Removing user fees for facility-based delivery services: a difference-in-differences evaluation from ten sub-Saharan African countries. Health Policy Plan 2015;30:432-41.

50 Witter S, Boukhalfa C, Cresswell JA, et al. Cost and impact of policies to remove and reduce fees for obstetric care in Benin, Burkina Faso, Mali and Morocco. Int J Equity Health 2016;15:123.

51 Witter S, Dieng T, Mbengue D, et al. The National free delivery and caesarean policy in Senegal: evaluating process and outcomes. Health Policy Plan 2010;25:384-92.

52 Witter S, Khalid Mousa K, Abdel-Rahman ME, et al. Removal of user fees for caesareans and under-fives in northern Sudan: a review of policy implementation and effectiveness. Int $\mathrm{J}$ Health Plann Manage 2013;28:e95-120.

53 MacKinnon N, St-Louis E, Yousef Y, et al. Out-Of-Pocket and catastrophic expenses incurred by seeking pediatric and adult surgical care at a public, tertiary care centre in Uganda. World J Surg 2018;42:3520-7.

54 Ouedraogo TL, Kpozehouen A, Gléglé-Hessou Y, et al. [Evaluation of free cesarean sections in Benin]. Sante Publique 2013;25:507-15.

55 Mongbo V, Ouendo E-M, De Brouwere V, et al. [Quality of caesarean delivery: A cross-sectional study in 12 hospitals in Benin]. Rev Epidemiol Sante Publique 2016;64:281-93.

56 Lange IL, Kanhonou L, Goufodji S, et al. The costs of 'free': Experiences of facility-based childbirth after Benin's caesarean section exemption policy. Soc Sci Med 2016;168:53-62.

57 Keya KT, Sripad P, Nwala E, et al. "Poverty is the big thing": exploring financial, transportation, and opportunity costs associated with fistula management and repair in Nigeria and Uganda. Int J Equity Health 2018;17:70.

58 Dankwah E, Kirychuk S, Zeng W, et al. Socioeconomic inequalities in the use of caesarean section delivery in Ghana: a cross-sectional study using nationally representative data. Int $J$ Equity Health 2019:18:162. 
59 Leone T, Cetorelli V, Neal S, et al. Financial accessibility and user fee reforms for maternal healthcare in five sub-Saharan countries: a quasi-experimental analysis. BMJ Open 2016;6:e009692.

60 El-Khoury M, Hatt L, Gandaho T. User fee exemptions and equity in access to caesarean sections: an analysis of patient survey data in Mali. Int J Equity Health 2012;11:49.

61 Ravit M, Audibert M, Ridde V, et al. Do free caesarean section policies increase inequalities in Benin and Mali? Int $J$ Equity Health 2018;17:71.

62 Touré L. User fee exemption policies in Mali: sustainability jeopardized by the malfunctioning of the health system. BMC Health Serv Res 2015;15 Suppl 3:S8.

63 Ridde V, Richard F, Bicaba A, et al. The National subsidy for deliveries and emergency obstetric care in Burkina Faso. Health Policy Plan 2011;26 Suppl 2:ii30-40.

64 Seyi-Olajide JO, Anderson J, Enivwaene AO, et al. Catastrophic healthcare expenditure from typhoid perforation in children in Nigeria. Surg Infect 2020;21:586-591.

65 Coulibaly Y, Togo A, Keita M. Cost of care for pediatric patients undergoing surgery at the university hospital Gabriel Toure. Medecine d'Afrique Noire 2010;57:198-202.

66 Mwandri M, Hardcastle TC, Sawe H, et al. Trauma burden, patient demographics and care-process in major hospitals in Tanzania: a needs assessment for improving healthcare resource management. Afr J Emerg Med 2020;10:111-117.

67 Honda A, Randaoharison PG, Matsui M. Affordability of emergency obstetric and neonatal care at public hospitals in Madagascar. Reprod Health Matters 2011;19:10-20.

68 Mostert S, Njuguna F, van de Ven PM, et al. Influence of healthinsurance access and hospital retention policies on childhood cance treatment in Kenya. Pediatr Blood Cancer 2014;61:913-8.

69 Blankson P-K, Nonvignon J, Aryeetey G, et al. Injuries and their related household costs in a tertiary hospital in Ghana. Afr J Emerg Med 2020;10:S44-9.

70 Rickard JL, Ngarambe C, Ndayizeye L, et al. Risk of catastrophic health expenditure in Rwandan surgical patients with peritonitis. World J Surg 2018:42:1603-9.

71 Adeniran AS, Aun II, Fawole AA, et al. Comparative analysis of caesarean delivery among out-of-pocket and health insurance clients in llorin, Nigeria. Niger Postgrad Med J 2020;27:108-14.

72 Rajaguru PP, Jusabani MA, Massawe H, et al. Understanding surgical care delivery in sub-Saharan Africa: a cross-sectional analysis of surgical volume, operations, and financing at a tertiary referral hospital in rural Tanzania. Glob Health Res Policy 2019;4:30.

73 Gichuru S, Kedera T, Wanjeri J, et al. Predictors of post-mastectomy breast reconstruction in Kenya. Annals of African Surgery 2020;17:16-20.

74 Okoroh J, Sarpong DO-B, Essoun S, et al. Does insurance protect individuals from catastrophic payments for surgical care? an analysis of Ghana's National health insurance scheme at Korle-Bu teaching hospital. BMC Health Serv Res 2020;20:45.

75 Bonfrer I, Breebaart L, Van de Poel E. The effects of Ghana's National health insurance scheme on maternal and infant health care utilization. PLoS One 2016;11:e0165623.

76 Stewart BT, Gyedu A, Abantanga F, et al. Barriers to essential surgical care in low- and middle-income countries: a pilot study of a comprehensive assessment tool in Ghana. World J Surg 2015;39:2613-21.

77 Dienye PO, Brisibe SF, Eke R. Sources of healthcare financing among surgical patients in a rural niger delta practice in Nigeria. Rural Remote Health 2011;11:1577.
78 Shrime MG, Sekidde S, Linden A, et al. Sustainable development in surgery: the health, poverty, and equity impacts of charitable surgery in Uganda. PLoS One 2016;11:e0168867.

79 Shrime MG, Verguet S, Johansson KA. Task-Sharing or public finance for expanding surgical access in rural Ethiopia: an extended cost-effectiveness analysis: disease control priorities. In: Essential surgery. . 3rd edn, 2015: Vol 1. 339-52.

80 Holoyda KA, Farhat B, Lalonde DH, et al. Creating an outpatient, local anesthetic hand operating room in a resource-constrained Ghanaian Hospital builds surgical capacity and financial stability. Ann Plast Surg 2020;84:385-9.

81 Gnassingbé K, Tekou H, da Silva-Anoma S, et al. The paediatric surgeon and his working conditions in Francophone sub-Saharan Africa. Afr J Paediatr Surg 2011;8:298-300.

82 Meda IB, Kouanda S, Dumont A, et al. Effect of a prospective payment method for health facilities on direct medical expenditures in a low-resource setting: a paired pre-post study. Health Policy Plan 2020;35:775-83.

83 Janssen W, Ngirabega JdeD, Matungwa M, et al. Improving quality through performance-based financing in district hospitals in Rwanda between 2006 and 2010: a 5-year experience. Trop Doct 2015;45:27-35.

84 Citron I, Jumbam D, Dahm J, et al. Towards equitable surgical systems: development and outcomes of a national surgical, obstetric and anaesthesia plan in Tanzania. BMJ Glob Health 2019;4:e001282.

85 Sonderman KA, Citron I, Mukhopadhyay S, et al. Framework for developing a national surgical, obstetric and anaesthesia plan. BJS Open 2019;3:722-32.

86 Okoroh JS, Chia V, Oliver EA, et al. Strengthening health systems of developing countries: inclusion of surgery in universal health coverage. World J Surg 2015;39:1867-74.

87 Saksena P, Antunes AF, Xu K, et al. Mutual health insurance in Rwanda: evidence on access to care and financial risk protection. Health Policy 2011;99:203-9.

88 Mensah J, Oppong JR, Schmidt CM. Ghana's National health insurance scheme in the context of the health MDGs: an empirical evaluation using propensity score matching. Health Econ 2010;19 Suppl:95-106.

89 Awori J, Strahle J, Okechi H, et al. Implications of patient-borne costs associated with pediatric neurosurgical care in eastern Africa. $J$ Neurosurg Pediatr 2016;18:116-24.

90 Shrime MG, Verguet S, Johansson KA. Task-Sharing or Public Finance for Expanding Surgical Access in Rural Ethiopia: An Extended Cost-Effectiveness Analysis. In: Debas HT, Donkor P, Gawande A, eds. Essential surgery: disease control priorities. Third Edition (Volume 1). Washington, DC: The International Bank for Reconstruction and Development / The World Bank (C) 2015 International Bank for Reconstruction and Development / The World Bank, 2015

91 Xu K, Evans DB, Kawabata K, et al. Household catastrophic health expenditure: a multicountry analysis. Lancet 2003;362:111-7.

92 Yap A, Cheung M, Kakembo N, et al. From Procedure to Poverty: Out-of-Pocket and Catastrophic Expenditure for Pediatric Surgery in Uganda. J Surg Res 2018;232:484-91.

93 World Health Organisation and International Bank for Reconstruction and Development/TheWorld Bank. Tracking universal health coverage: 2017 global monitoring report. Geneva: World Health Organisation and International Bank for Reconstruction and Development/TheWorld Bank, 2017.

94 World Health Organisation. Monitoring Sustainable Development Goals - Indicator 3.8.2, 2020. Available: https://www.who.int/health financing/topics/financial-protection/monitoring-sdg/en/ [Accessed 17 Dec 2020]. 